\title{
Indicadores na gestão universitária: uma metodologia de apoio
}

Indicators on university management: a support methodology

Antonio Carlos Miranda*

Centro Universitário Salesiano de São Paulo

Resumo $\mathrm{O}$ mote deste manuscrito é apresentar a construção e o uso de indicadores no processo de autoavaliação de uma universidade, como orientado pelo Sistema Nacional de Avaliação do Ensino Superior (Sinaes). $\mathrm{O}$ uso de indicadores possibilita auxiliar a gestão da informação na instância decisória da instituição, principalmente em tempos em que a produção da informação é abundante. Neste estudo, utilizaram-se dados da avaliação realizada pelo corpo discente entre 2008 e 2010 do Centro Universitário Salesiano de São Paulo (Unisal). Os resultados mostraram que a produção de indicadores deve ter legitimidade técnica, política e que deve ser produzida coletivamente dentro da instituição, pois somente a partir de um processo que reúne informações e dados coletivos pode-se estimular a análise reflexiva das práticas em busca de melhorias em todos os níveis.

PALAVRAS-CHAVE: Ensino superior; Avaliação; Gestão.

Abstract The focus of this manuscript is to present the construction and use of indicators in a university self-assessment process, as directed by the Higher Education National Evaluation System (SINAES). The use of indicators allows giving support in the information management in order in the decision-making of the institution, especially when the information production is abundant. In this study was used evaluation data done by students between 2008 and 2010 of the Salesiano University Center of São Paulo (Unisal). The results showed that indicator productions must have the technical, political legitimacy and must be collectively produced within the institution, because only from a process that gathers information and collecting data it can stimulate a reflective analysis of practices into search of improvements at all levels.

KEYWORDS: Higher education; Evaluation; Management. 


\section{Introdução}

Este artigo tem como objetivo apresentar a utilização de alguns indicadores no processo de autoavaliação do Centro Universitário Salesiano de São Paulo (Unisal), usando dados da avaliação das disciplinas realizadas pelo corpo discente entre 2008 e 2010. O Unisal é um centro multicampi no estado de São Paulo, com unidades universitárias nas cidades de São Paulo, Americana, Lorena, e Campinas. Dada sua característica multicampi, os processos de gestão da qualidade estão intrinsecamente ligados a uma visão estratégica que considera de forma particular a visão macro dos processos de avaliação, ao mesmo tempo, que considera as especificidades de cada unidade universitária, por isso, a busca constante de técnicas e metodologias que de forma complementar, auxiliem na tomada de decisão.

O uso de indicadores pode se constituir, por sua natureza, em importante elemento a ser explorado no tratamento dos dados na avaliação institucional do ensino superior, principalmente nos relatórios de autoavaliação do Sistema Nacional de Avaliação do Ensino Superior (Sinaes).

Em tempos em que a produção da informação é abundante no ensino superior, nem sempre as instituições se apropriam dos dados produzidos a cada avaliação de forma a explorar as possibilidades oferecidas por um estudo de base quantitativa.

$\mathrm{O}$ uso de indicadores possibilita auxiliar a gestão da informação na instância decisória da instituição, principalmente quando se trata de dados quantitativos, com grande volume de informação, como um questionário aplicado ao corpo discente.

O sistema de avaliação tem suas concepções fortemente vinculadas
aos interesses sociais da educação superior, para tanto a avaliação
institucional é um instrumento central e organizador da coerência
deste conjunto da autoavaliação, tendo como um de seus propósitos,
produzir material que contribua para a cultura da avaliação nas ins-
tituições, como um mecanismo de aperfeiçoamento dos processos
internos. (SINAES, 2009, p. 102).

O processo de avaliação precisa dar conta de buscar os problemas, as divergências, as dúvidas, os pontos fortes e os de melhoria, pois além de diagnosticar, precisa possibilitar discussão, análise conjunta e tomada de decisão. Nesse aspecto, a função da avaliação passa a ser transformadora e propositiva, com isso se busca mudança nas ações. Contudo, com essa função, as medidas quantitativas isoladas são insuficientes. Há a necessidade dos números, das medidas, da estatística como meio que possibilitará análises e discussões conjuntas.

Nessa perspectiva, quantidade e qualidade são dimensões inseparáveis de uma mesma realidade. Dias Sobrinho (1997) corrobora essa ideia e diz:

Se queremos conhecer objetivamente o estado de uma determinada realidade, precisamos construir numerosos indicadores quantitativos, lembrando sempre que a dimensão qualitativa aí também se apresenta, pois todas as atividades humanas são orientadas por critérios sociais e escolhas pessoais ou intersubjetivas. (DIAS SOBRINHO, 1997, p. 83). 
Freitas (2001), discutindo as implicações conceituais para uma prática avaliativa, afirma que "a avaliação é um processo dinâmico e de permanente acomodação e, portanto, a definição dos parâmetros de avaliação e dos indicadores deve ser concretizada em uma tensão entre aquilo que são os interesses e os compromissos" do curso e da instituição. Portanto, se faz necessário levar em consideração as concepções de educação, de sociedade, de mundo que estão configuradas no Plano de Desenvolvimento Institucional (PDI), nos Projetos pedagógicos dos cursos e nas diretrizes nacionais.

Mediante o cenário nacional, o desenvolvimento da avaliação institucional passou a ser um processo obrigatório. As experiências em relação a esta temática têm revelado, entretanto, que é necessário que os princípios orientadores destes processos devem ser construídos e conhecidos por todos, de forma a conseguir um maior envolvimento.

Por um lado, segundo Freitas (2001) "a avaliação é uma categoria intrínseca do processo ensino-aprendizagem”, e, por outro, do Plano de Desenvolvimento Institucional (PDI); deve ser feita pelo e para o professor e/ou aluno e seu coletivo imediato - a instituição. Deve-se ter claro o mote principal da avaliação, e este deve gerar no mínimo reflexão, ou seja, nenhuma das ações de avaliação deve conduzir ao "ranqueamento" ou classificação de qualquer natureza e muito menos deve conduzir à premiação ou punição.

Enfim, a avaliação sempre foi e sempre será um constante desafio em qualquer nível e, para tanto, a transparência, o conjunto de técnicas aplicadas e os resultados obtidos devem ser acessíveis.

\section{Indicadores educacionais}

A discussão do conceito de indicadores educacionais apareceu em 1862, de acordo com Reali (2001), quando teve início a implantação da educação de "massa" nos Estados Unidos e que implicou concomitantemente na realização de estudos avaliativos.

A característica básica dos indicadores educacionais é a capacidade de sintetizar um conceito qualquer através do agrupamento de diversas variáveis. As implicações e especificações destes indicadores variam de acordo com os estudos, entretanto, tanto em nível nacional como internacional, seu foco coincide no que diz respeito à busca de formas adequadas à elevação dos níveis de desempenho dos alunos, sendo imprescindível à análise do contexto para a compreensão dos resultados obtidos (INEP, 2004, p. 45), principalmente por se tratar de variáveis relativas.

A estrutura dos indicadores internacionais mantém uma diretriz geral de agrupamentos, de acordo com Vitória (1995), ou seja, há indicadores de contexto, recursos, processo e resultado.

Não se pode perder de vista que a informação dada pelo indicador, segundo Bottani (1998), deve "estimular a formação e o controle empírico de hipóteses explicativas alternativas, caso contrário, não teria sentido construir estes indicadores”. A 
literatura citada nos alerta que os indicadores atuam para sinalizar sobre o fato de que "alguma variável" pode estar influenciando, tanto de maneira positiva quanto negativa, o sistema escolar, não facultando a necessidade de se investigar todas as variáveis envolvidas (MIRANDA, 2006).

A principal contribuição dos indicadores é iluminar a realidade, fornecendo elementos de juízo para interpretá-la (BRYK \& HERMANSON, 1993). Ademais, os indicadores educacionais devem informar, trazendo dados que favoreçam a reflexão de todos os atores, ajudando-os na compreensão da complexidade das instituições e dos processos educacionais em diferentes âmbitos. Afinal, um sistema de indicadores ou construtos, isoladamente, não faz a diferença nos resultados da aprendizagem dos alunos ou nas práticas dos professores. Com isso, para Miranda (2006, p. 33), "o ponto crucial parece ser a escolha das variáveis adequadas para a organização dos indicadores em função dos objetivos determinados, ou melhor, na medida em que se pretende encontrar respostas possíveis".

Ainda hoje existem poucas discussões sobre a construção de indicadores, contudo, neste quesito é necessário que haja uma discussão aprofundada para se viabilizar o uso destas medidas cumulativas, que são usadas com frequência na pesquisa social.

De acordo com Babbie (1999, p. 213), "apesar do cuidado ao se construir questionários, raramente é possível chegar a uma única pergunta que represente adequadamente um conceito", como já citado aqui. Por conseguinte, com o uso de índices e escalas combinadas, através de diversos itens de questionários, se consegue minimizar as possíveis distorções inerentes ao uso de itens únicos.

Nas análises preliminares dos dados, usualmente, trabalhamos com a estatística descritiva, que considera em um primeiro momento as análises univariada e bivariada, revelando apenas a possibilidade de uma leitura rudimentar dos dados. Sendo impraticável considerar simultaneamente todas as respostas particulares dadas por todos os respondentes, a construção de um indicador pode reduzir estas respostas a uma única medida e, mesmo assim, os detalhes específicos daquelas respostas serem mantidos quase na totalidade. Um indicador pode ser construído pela somatória simples de escores atribuídos a respostas específicas aos itens individuais que formam o índice (BABBIE, 1999).

\section{Metodologia}

Considerando os cursos anuais e/ou semestrais no período de 2008 a 2010, o UNISAL aplicou um questionário de avaliação de disciplinas ministradas nos cursos de graduação, de forma online, através da intranet institucional. Ao aluno é facultativo o preenchimento do questionário, entretanto, se optar em fazê-lo, seu preenchimento é obrigatório em todos os itens.

Em um primeiro momento, a avaliação considerou as seguintes variáveis: unidade, campus, série, turno, curso, disciplina e mais 25 questões referentes à: disciplina, desempenho docente, autoavaliação discente; em uma escala de 1 a 5 , sendo 5 o conceito excelente. 
O propósito desta avaliação foi determinar se há possibilidade de formar um constructo, que abrange um amplo conceito através de associações de diferentes variáveis que geram um indicador (FRANCO et al, 2003).

A tabela 1 apresenta o número de respostas obtidas por unidade universitária e os respectivos períodos letivos de 2008 até 2010, totalizando 122.554 respostas dos questionários de disciplina do Unisal.

Tabela 1: Total de respostas por Campus e por período letivo

\begin{tabular}{l|l|l|l|l|l|l|l|l|l|l}
\hline \multicolumn{10}{c}{ Período Letivo } \\
\hline Campus & 2008 & 2009 & 2010 & $2008-1$ & $2008-2$ & $2009-1$ & $2009-2$ & $2010-1$ & $2010-2$ & Total \\
\hline Americana & 4805 & 1735 & 444 & 6921 & 5914 & 2642 & 6669 & 9007 & 8324 & 46461 \\
\hline Campinas & 756 & 214 & 203 & 4541 & 3629 & 3105 & 2702 & 4225 & 4084 & 23459 \\
\hline Lorena & 2250 & 112 & 0 & 8323 & 7211 & 6431 & 5420 & 7036 & 5073 & 41856 \\
\hline São Paulo & 1016 & 34 & 46 & 1903 & 1466 & 1339 & 1368 & 1919 & 1687 & 10778 \\
\hline Total & 8827 & 2095 & 693 & 21688 & 18220 & 13517 & 16159 & 22187 & 19168 & 122554 \\
\hline
\end{tabular}

Fonte: CPA 2010.

Com base nestes dados foram criados três indicadores: indicador de disciplina, desempenho docente e autoavaliação discente. Estes indicadores tiveram como objetivo traçar uma perspectiva macro da percepção do aluno em relação às disciplinas oferecidas e concomitantemente viabilizar os estudos longitudinais da instituição. A simples compilação de dados não garante sua eficácia na construção, tão importante quanto processar os dados de forma sistemática é garantir que sua análise seja feita através de técnicas adequadas que possam resultar em estimativas eficientes e, consequentemente, garantir reflexões analíticas detalhadas e profundas (FIGUEIREDO FILHO et al, 2013).

Mediante nossos dados categóricos, a análise das respostas foi realizada considerando o modelo da teoria da resposta ao item não paramétrica, proposto por Mokken (1971), conhecido como "H de Mokken", que mede o grau de associação entre um par de itens e entre o item e os outros que compõem todo o indicador. Este modelo permite examinar quanto o valor do indicador construído se afasta de uma escala perfeita (determinística), apresentando o coeficiente H de Loevinger (MOKKEN, 1971).

Estas escalas são formuladas com o objetivo de reduzir os dados, uma vez que a ideia é agrupar várias respostas de uma mesma pessoa para chegar a um único valor, que representa uma medida para o conceito latente que queremos estudar. Enfatizando que as respostas estão pré-determinadas, logo, o respondente precisa se posicionar, em razão disso, abre-se mão de conclusões pontuais, centradas no indivíduo.

Assim, os pressupostos mínimos para a construção destes indicadores seguiram as orientações básicas de Babbie (1999): 
- A seleção dos itens, que considerou cautelosamente a quantidade de variância fornecida pelos mesmos;

- A unidimensionalidade, que representa uma medida composta de itens latentes refletindo o mesmo conceito;

- O coeficiente de correlação, das possíveis relações bivariadas entre os itens que reflete a força relativa dos mesmos.

Para aplicação das análises estatísticas, foi usado o software estatístico Statistical Package for the Social Sciences (SPSS), versão 15.0.

\section{Indicador de disciplina}

As variáveis contempladas neste indicador foram: plano de ensino, objetivos, programa, carga horária, material didático, como o aluno avalia a disciplina e integração entre as disciplinas.

Primeiramente, a análise descritiva de cada variável nos mostrou sua consistência e, em seguida, pode-se estudar a variabilidade de cada item, checar sua unidimensionalidade e, por fim, testar todas as combinações possíveis entre os itens e usar suas possíveis correlações.

Esta análise resultou na criação do constructo conceitual denominado "Indicador de Disciplina”. Mediante este constructo, foi possível realizar diferentes análises e abordagens metodológicas para checar seu impacto em diferentes níveis. Como exemplo, os gráficos 1 e 2 apresentam a distribuição do constructo por período letivo e por série.

No gráfico 1, é possível identificar a variabilidade do indicador que foi de 7 a 35 , e sua mediana 28 em todos os períodos, o que representa $80 \%$ da pontuação máxima, podendo considerar entre boa e excelente.

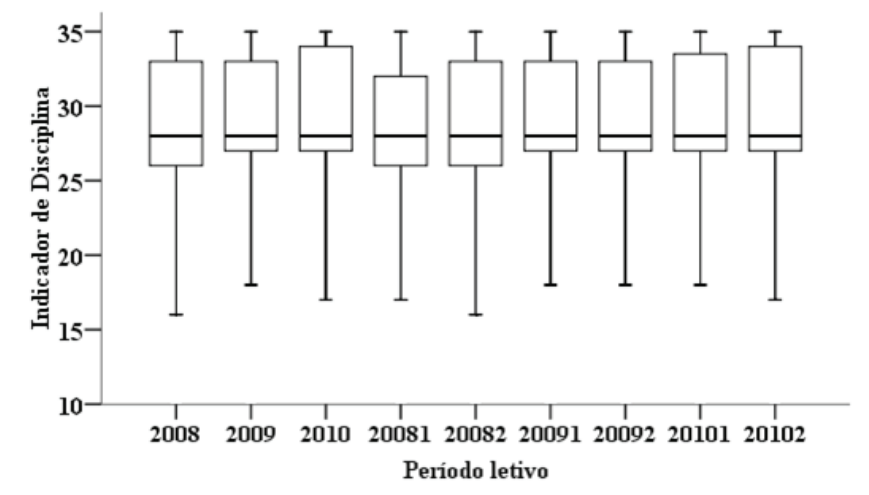

Gráfico 1: Indicador da avaliação de disciplina por período letivo. Fonte: CPA 2010.

Todavia, para conhecer o comportamento do indicador, foi necessário checar sua distribuição detalhadamente, não só sua mediana, mas também sua média, seus quartis e se existem valores extremos. No gráfico 1, o período letivo de 2009 dos cursos 
anuais apresentou uma concentração de valores acima da mediana e uma distribuição não simétrica, sugerindo um viés de alta nas médias do ano letivo; apesar de sua mediana. $\mathrm{Na}$ avaliação das turmas semestrais de 2009-1S e 2009-2 houve uma melhora na distribuição do indicador, que variou de 27 a 33, e em 2010-1S e 2010-2S variou de 27 a 34 .

Já o gráfico 2 apontou para uma tendência de baixa deste indicador na avaliação dos alunos das séries finais; embora a mediana (28) entre as séries fosse a mesma, a média das primeiras séries (29) é maior do que as das séries finais (26), com uma concentração de valores abaixo da linha da mediana no $9^{\circ}$ semestre. Isso representa uma diferença importante entre os alunos que iniciam o curso superior e aqueles que estão terminando, refletindo basicamente a maturidade, a visão crítica e o grau de exigência que os alunos ganham no decorrer dos cursos.

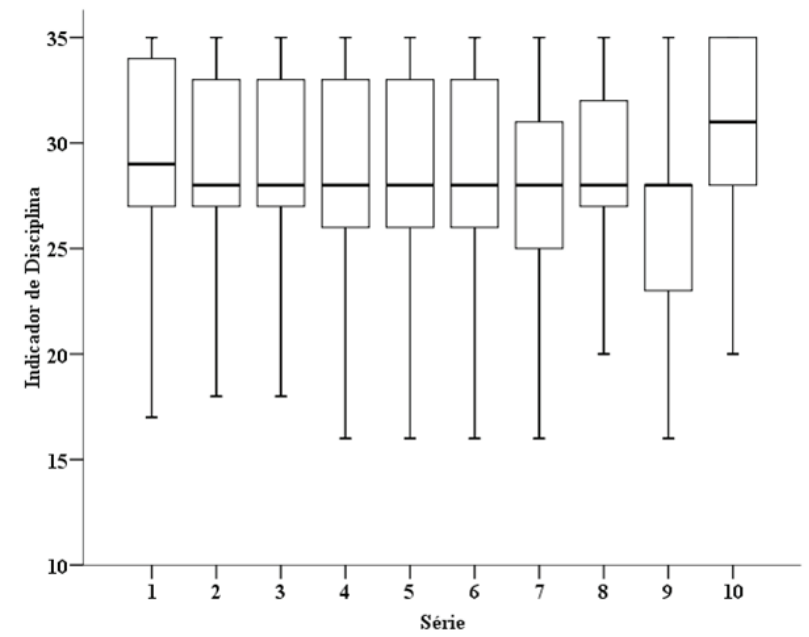

Gráfico 2: Indicadores da avaliação de disciplinas por série. Fonte: CPA 2010.

O indicador ainda possibilita muitas outras análises, estratificando por séries balanceadas por números de alunos, por cursos, por turnos, cotejando as unidades universitárias, entre outras. O importante é entender o conceito deste constructo, o que os valores representam no panorama da instituição para propor ações basicamente ligadas ao trabalho pedagógico.

\section{Indicador de desempenho docente}

Foram contempladas 11 variáveis na composição deste indicador, sendo: coerência entre as aulas ministradas e as avaliações; clareza com que o professor avalia a disciplina; o domínio e atualização do professor; preparação das aulas; adequação dos recursos audiovisuais nas aulas; incentivo do professor ao aluno; atendimento do professor para com o aluno; relacionamento do professor com a classe; valores institucionais nas atitudes dos professores; aproveitamento do tempo de aula pelo professor e desempenho geral do professor 
Estas variáveis resultaram no indicador chamado desempenho docente. Este constructo tentou compor as questões relacionadas ao ensino docente. Sua variabilidade foi de 43 a 54, com a mediana de 44, denotando uma avaliação de boa a excelente aos professores de maneira geral.

O gráfico 3 mostra a distribuição deste indicador por período letivo. O que chama a atenção neste gráfico é que a média do indicador subiu de 45 em 2009 para 46 em 2010, o que representou respectivamente $82,9 \%$ e $84 \%$ do valor máximo do indicador, ou seja, indicadores classificados entre bom e excelente.

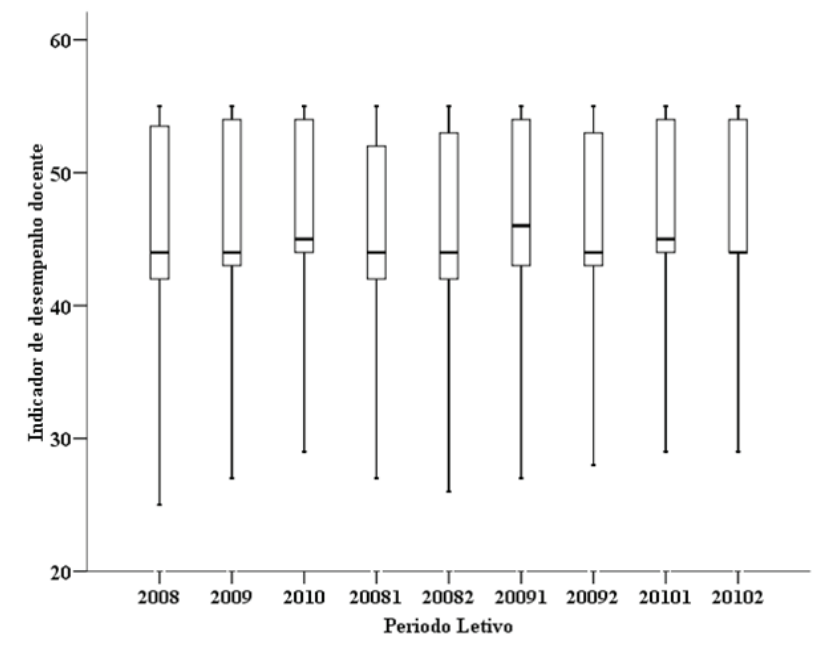

Gráfico 3: Indicador de desempenho docente por período letivo. Fonte: CPA 2010.

Outro aspecto importante é que o indicador de desempenho docente está fortemente correlacionado com o indicador de disciplina (88\%), o que reflete a coerência do aluno na avaliação dos dois indicadores, os quais estão interligados de forma única pelo trabalho pedagógico.

\section{Indicador de autoavaliação discente}

$\mathrm{O}$ indicador de autoavaliação discente foi gerado a partir de seis perguntas: interesse pelas atividades desenvolvidas na disciplina; participação do aluno nas atividades extraclasse; leituras da bibliografia; interesse pela disciplina; progresso na disciplina e relacionamento professor aluno.

O gráfico 4 apresenta o indicador de autoavaliação discente e pode-se inferir que, quando fazem uma autoavaliação, os alunos parecem ser mais rigorosos à medida que, se aproximam da conclusão do curso e esta relação também ocorre nos indicadores de disciplina e de desempenho docente. Os indicadores do sétimo e nono semestres estão nos grupos com os menores desempenhos relativos. 


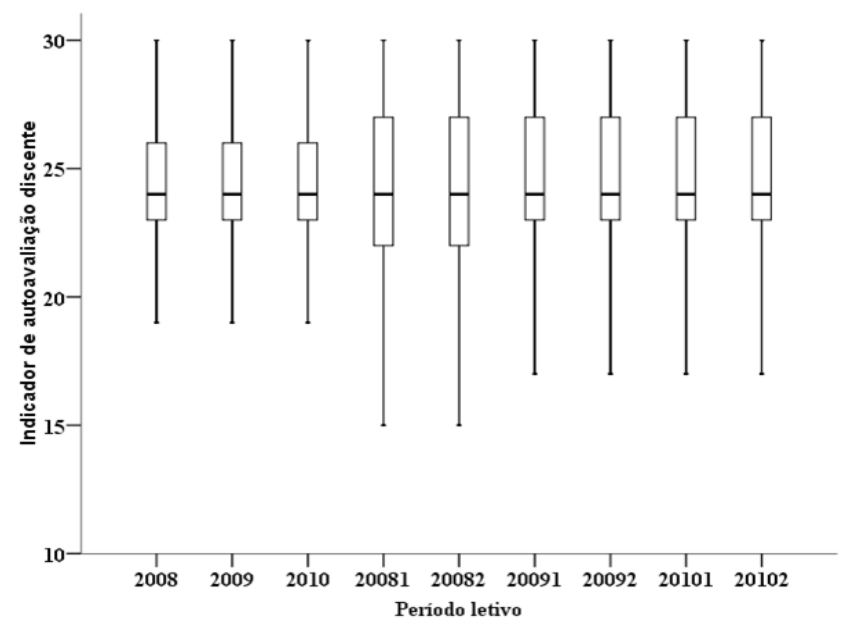

Gráfico 4: Indicador de desempenho de autoavaliação discente. Fonte: CPA 2010.

A média deste indicador dos primeiros semestres foi 24 (81,7\%), refletindo que os alunos consideraram, em média, que o seu desempenho está entre bom e excelente; já a partir do sétimo semestre, a concentração dos dados se apresenta abaixo da mediana.

Nestes casos, é recomendado aplicar a análise qualitativa para entender e explicar o porquê da queda dos indicadores nas séries mais altas, considerando outras variáveis de impacto direto ou indireto na avaliação do discente.

Outra maneira foi investigar, primeiramente, se estas diferenças se manteriam quando o indicador fosse cotejado pela unidade, e o que se constatou foi que os alunos de Americana, Lorena e São Paulo se avaliaram de forma mais positiva no que tange ao seu compromisso com os estudos, apresentando uma distribuição assimétrica acima da mediana (gráfico 5).

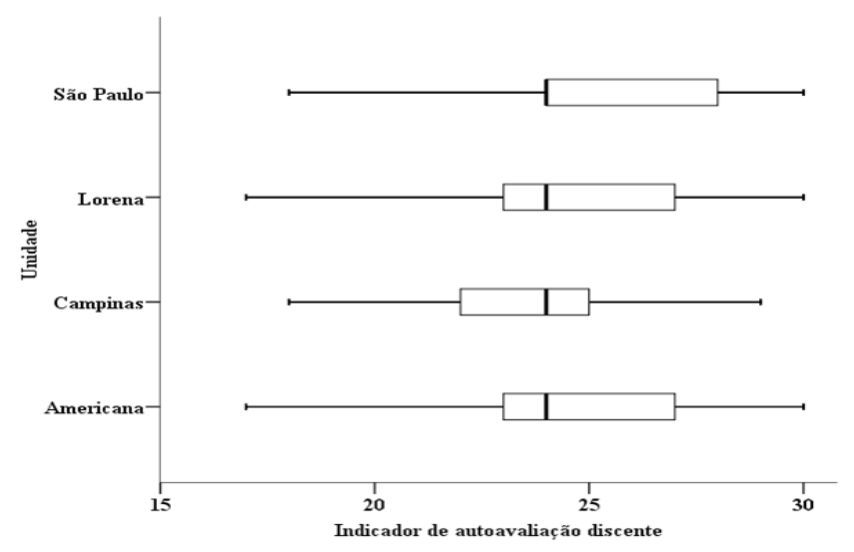

Gráfico 5: Indicador de autoavaliação discente por unidade. Fonte: CPA 2010. 
O histograma (Figuras 1, 2 e 3 ) de cada indicador nos mostra quais as maiores frequências e como foi a variabilidade de cada um, sinalizando o padrão geral da avaliação.

Enfim, a criação dos indicadores possibilitou não só diferentes análises, mas principalmente um entendimento mais amplo de conceitos fundamentais na busca de qualidade de ensino, pois, através de seu uso com as estratificações, foi possível identificar tanto fatores positivos quanto negativos e localizar onde era necessária uma atuação diferenciada.

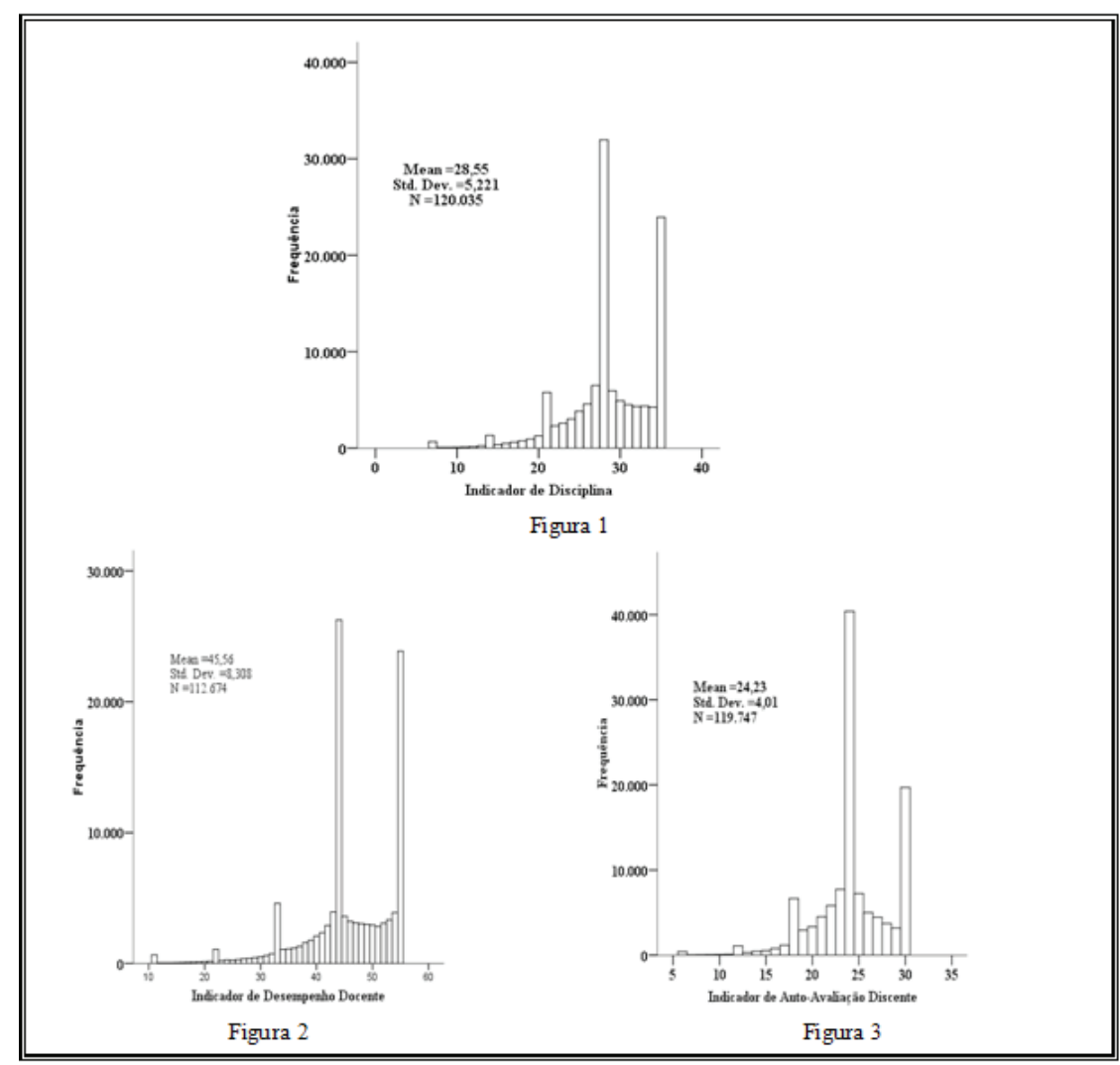

Figuras 1, 2 e 3: Distribuição dos indicadores: disciplina, desempenho docente e autoavaliação discente.

\section{Considerações do processo avaliativo}

De maneira geral, Silva e Gomes (2011) enfatizam certas limitações do trabalho desempenhado pela CPA na autoavaliação e questionam o propalado conflito entre avaliação e regulação. Indubitavelmente, devemos considerar as idiossincrasias e, a medida do possível, superar os conflitos e limitações impostos por fatores internos ou externos à instituição, afinal, a avaliação institucional é um processo relativamente recente no Brasil, e demanda ajustes constantes a partir das necessidades apontadas por instituições e órgãos de regulação. 
A cultura da avaliação na instituição está intrinsecamente ligada às melhorias implementadas a partir dos resultados da avaliação, sendo assim, a técnica de base da análise dos dados, seja quantitativa ou qualitativa, ganha importância estratégica, porque são responsáveis por indicar tendências, apontar caminhos e propor ações de melhoria.

No âmbito da avaliação institucional, o parâmetro inicial foi a autoavaliação seguida pelo diálogo entre a Comissão Própria de Avaliação (CPA) e a Comissão de Gestão Estratégica (CGE), com o mote de consolidar e elaborar os laudos das avaliações.

Neste contexto, o processo avaliativo foi concebido como construtivo e global. Envolveu participantes internos (professores, alunos, especialistas, funcionários administrativos) e participantes externos (sociedade, empregadores, egressos), pois desde o início foi tratado como um processo que combinou autoavaliação, avaliação por pares e também um olhar externo.

A descrição dos indicadores de disciplina, de desempenho docente e de autoavaliação discente foi construída a partir da reflexão coletiva no âmbito da Comissão Própria de Avaliação (CPA), considerando, de forma particular, a apresentação do relatório a comunidade, utilizando tabelas, gráficos e descrições dos resultados.

Os laudos das avaliações foram analisados de maneira minuciosa pelos Grupos de Qualidade das unidades e dos cursos. A partir destas análises, ocorridas ao longo de cada ano avaliado, o grupo elaborou um plano de melhorias para a unidade e os cursos a serem desenvolvidos no ano seguinte. O plano de melhorias foi apresentado ao conselho de cada unidade e/ou ao colegiado de cada curso, que deliberaram a operacionalização e o acompanhamento das ações aprovadas.

No que concerne ao processo de ensino-aprendizagem, os resultados das avaliações foram disponibilizados por disciplina, para que os professores pudessem aprimorar suas estratégias de ensino e avaliação, preservando a autonomia profissional e, concomitantemente, valorizando a atuação responsável do professor no processo pedagógico. Além disso, os professores contavam com o suporte do Núcleo de Apoio Pedagógico (NAP) do Unisal, que tem como uma de suas finalidades desenvolver programas de apoio ao docente na organização do trabalho pedagógico.

A CPA incentiva, assessora e registra todas as ações dos Grupos de Qualidade. Com este processo conjunto, participativo e contínuo de trabalho, procura-se garantir que os resultados das avaliações sejam interpretados e utilizados da melhor maneira possível pelos próprios avaliados, que são os principais protagonistas de seu desenvolvimento.

\section{Discussão}

A obtenção dos indicadores, neste estudo, foi possível na medida em que seguiu todos os pressupostos estabelecidos para a construção de cada constructo, ou seja, as perguntas selecionadas tiveram suas respostas analisadas e somente quando a vari- 
ância e a unidimensionalidade estavam dentro do esperado, eram elegíveis para tentar compor o indicador. Posteriormente, este conjunto de perguntas teve suas respostas analisadas, através do coeficiente de correlação, que determinava a força relativa dos mesmos dentro do indicador. E por fim, este conjunto de medidas resultava na composição de cada indicador. Obviamente, diversas perguntas não entraram na composição, pois não contemplaram algum dos pressupostos. Por conseguinte, o modelo dos indicadores, apoiado nas respostas, com propriedades estatísticas preservadas, refletiu como uma fotografia panorâmica em um dado espaço e tempo, fornecendo subsídios para encontrarmos soluções aos problemas, sistematização e trabalho conjunto.

Em geral, as técnicas quantitativas serão cada vez mais necessárias, devido às características de análise de grandes populações de um período. Assim, a coleta de dados quantitativos deve fornecer informações que permitam responder aos questionamentos a que se propõe avaliar. E para que os resultados possam ser confiáveis, tanto a coleta dos dados quanto o processo de análise deve ter tratamento objetivo, transparente e rigoroso.

Cabe salientar que a indissociabilidade no âmbito educativo é clara, não só devido a multiplicidade de fatores inter-relacionados, mas, principalmente, devido a complexidade e instabilidade destes fatores. Portanto, como cita De Sordi (2011), "o uso das metodologias devem ser complementares, quantitativa e qualitativa, à medida que pede o problema na sua complexidade".

Este estudo mostrou o uso de indicadores institucionais como estratégias de interpretação dos vários elementos que compõem a autoavaliação. A interpretação quantitativa dos indicadores, bem como do relatório descritivo das avaliações de disciplinas, gerou um relatório ressaltando os aspectos positivos, aspectos a aperfeiçoar e sugestões de ações de melhorias no âmbito do curso e unidade.

Tavares, Oliveira e Seiffert (2011) corroboram afirmando que "o processo de autoavaliação, segundo uma visão emancipatória, deveria promover com apoio da comunidade acadêmica e da externa, de forma democrática e participativa, uma autoavaliação que permitisse tomar consciência das suas potencialidades e limitações".

O projeto de avaliação institucional do Unisal parte do pressuposto básico de que a avaliação não deve ser um instrumento de controle sobre a instituição e os profissionais da educação, mas sim um processo que reúna informações e dados para alimentar e estimular a análise reflexiva das práticas em busca de melhorias. Dessa forma, o "modelo" de qualidade e seus "indicadores" devem ter legitimidade técnica e política e serem produzidos coletivamente dentro da instituição, a partir da prática.

\section{Referências}

BABBIE, E. Métodos de pesquisa de survey. Tradução de Guilherme Cezarino. Belo Horizonte, Editora da UFMG, 1999.

BOTTANI, N. Los indicadores educativos de la OCDE: objetivos, límites y procesos de producción. Perspectivas: revista trimestral de educación comparada, v. 23, n. 28, p. 69-85, marzo, 1998. 
BRASIL. Ministério da Educação/INEP. Resultados do SAEB 2003. Versão preliminar. Brasília, DF, jun. 2004. Disponível em: <www.inep.mec.gov.br>. Acesso em: 02 mar. 2015.

BRYK, A. S.; HERMANSON, K. L. Educational indicator systems: Observations on their structure, interpretation and use. Review of Research in Education, v. 19, p. 451-484, 1993.

DE SORDI, M. R. L. Comissão própria de avaliação (cpa): similaridades e dessemelhanças no uso da estratégia na educação superior e em escolas do ensino fundamental. Avaliação, Campinas, Sorocaba, v. 16, n. 3, p. 603-617, 2011. Disponível em: <http://scielo.br/scielo >. Acesso em: 12 dez. 2011.

DIAS SOBRINHO, J. Campo e Caminhos da Avaliação: a avaliação da educação superior do Brasil. In: FREITAS, L. C. de (Org.). Avaliação: construindo o campo e a crítica. Florianópolis: Insular, 2002.

FIGUEIREDO FILHO, D. B. et al. Análise de componentes principais para construção de indicadores sociais. Revista Brasileira de Biometria, São Paulo, v. 31, n. 1, p. 61-78, 2013.

FRANCO,C.etal.Oreferencial teórico na construção dos questionários contextuais do Saeb 2001. Estudos em Avaliação Educacional, São Paulo, n. 28, dez. 2003. Disponível em:<http://educa. fcc.org.br/scielo.php?script=sci_arttext\&pid=S0103-68312003000200003\&lng=pt\&nrm=iso > Acesso em 17 jun. 2015.

FREITAS, L. C. Implicações conceituais para a prática avaliativa. Palestra proferida aos membros da Comissão Central de Graduação da UNICAMP. Campinas, São Paulo. 22 fev. 2001, mimeo.

MIRANDA, E. C. M. O SAEB-2003 no estado de São Paulo: um estudo multinível. 2006. 216 p. (Dissertação de mestrado) - Universidade Estadual de Campinas UNICAMP, Campinas, SP.

MOKKEN, R.J. A Theory and procedure of scale analysis. Berlin: Mouton/De Gruyter, 1971.

REALI, A. M. M. R. Indicadores educacionais, professores e a construção do sucesso escolar. Ensaio: Avaliação e Políticas Públicas em Educação, Rio de Janeiro, v. 9, n. 30, p.79-108, 2001.

SILVA, A. L.; GOMES, A. M. Avaliação institucional no contexto do sinaes: a cpa em questão. Avaliação, Campinas, Sorocaba, v. 16, n. 3, p. 573-601, 2011. Disponível em: <http://scielo.br/ scielo>. Acesso em: 08 dez. 2011.

SINAES. INEP. Sistema Nacional de Avaliação da Educação Superior: da concepção à regulamentação. 5. ed. ampl. Brasília: INEP, 2009, 328p.

TAVARES, M. G. M.; OLIVEIRA, M. A. A.; SEIFFERT, O. M. L. B. Avaliação da educação superior na revista Ensaio: avaliação e políticas públicas em educação: ênfases e tendências. Ensaio: Avaliação e Políticas Públicas em Educação, Rio de Janeiro, v. 19 , n. 71 , p. 233-258, 2011.

UNISAL - Projeto de Avaliação Institucional, 2004 a 2006, mimeo.

VITÓRIA, F. M. Modelos y ezemplos in indicadores educativos. Cuadernos de Pedagogia. 256:54-61, mar. 1995. In: RODRIGUES, S. C. Construção de uma metodologia alternativa para a avaliação das escolas públicas de ensino fundamental através do uso da análise por envoltória de dados (DEA): uma associação do quantitativo ao qualitativo. 2005. Tese (doutorado) - Universidade Estadual de Campinas UNICAMP, Campinas, SP. 
Antonio Carlos Miranda

\section{Correspondência}

Antonio Carlos Miranda - Centro Universitário Salesiano de São Paulo, Programa de Mestrado em Educação do Unisal. Avenida de Cillo - 3500, Parque Novo Mundo, CEP: 13467-600, Americana, São Paulo - Brasil.

E-mail:miranda.ac@uol.com.br

Recebido em 23 de abril de 2014

Aprovado em 31 de março de 2015 